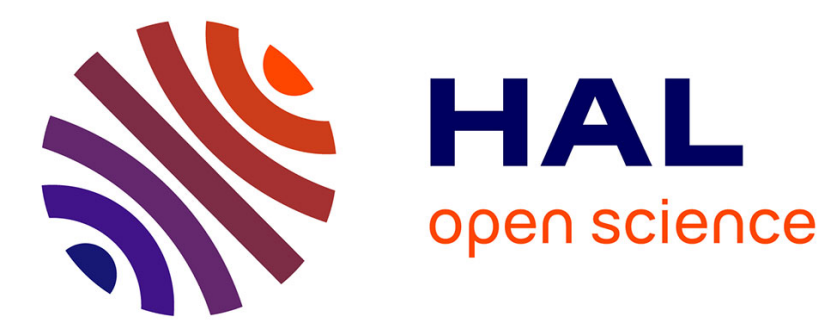

\title{
3D periodic BE-FE model for various transportation structures interacting with soil
}

H. Chebli, Ramzi Othman, Didier Clouteau, M. Arnst, G. Degrande

\section{To cite this version:}

H. Chebli, Ramzi Othman, Didier Clouteau, M. Arnst, G. Degrande. 3D periodic BE-FE model for various transportation structures interacting with soil. Computers and Geotechnics, 2008, 35 (1), pp.22-32. 10.1016/j.compgeo.2007.03.008 . hal-01004674

\section{HAL Id: hal-01004674 \\ https://hal.science/hal-01004674}

Submitted on 12 Feb 2017

HAL is a multi-disciplinary open access archive for the deposit and dissemination of scientific research documents, whether they are published or not. The documents may come from teaching and research institutions in France or abroad, or from public or private research centers.
L'archive ouverte pluridisciplinaire HAL, est destinée au dépôt et à la diffusion de documents scientifiques de niveau recherche, publiés ou non, émanant des établissements d'enseignement et de recherche français ou étrangers, des laboratoires publics ou privés. 


\title{
3D periodic BE-FE model for various transportation structures interacting with soil
}

\author{
H. Chebli ${ }^{\mathrm{a}, *}$, R. Othman ${ }^{\mathrm{a}}$, D. Clouteau ${ }^{\mathrm{a}}$, M. Arnst ${ }^{\mathrm{a}, \mathrm{b}}$, G. Degrande ${ }^{\mathrm{b}}$ \\ a MSSMat Laboratory, Ecole Centrale Paris, France \\ ${ }^{\mathrm{b}}$ Department of Civil Engineering, K. U. Leuven, Belgium
}

\begin{abstract}
A three-dimensional model for soil-transportation structures is presented. This model exploits the geometrical periodicity of the system and takes into account the dynamic soil-structure interaction with a methodology coupling a boundary element method for the soil and a finite element formulation for the structure. A general overview of this approach is given based on several real transportation structures. Moreover, comparative studies between the different structures have been carried out. Then the model is improved by introducing a general rule for the determination of the optimal number of cells. Finally, the periodic modes propagation is investigated offering a first seizing of the significant dynamical phenomena in the soil-structure system.
\end{abstract}

Keywords: Periodic model; BE-FE coupling; Dynamic soil-structure interaction; Floquet-Shannon criterion; Periodic modes propagation; Railway track; Tunnel

\section{Introduction}

Vibrations induced by transport vehicles are of a major concern since they have an important impact on the human comfort and the built environment but also on the degradation of the track components (for instance the ballast layer in the case of a ballasted railway track). Various problems related to these perturbations have been already addressed such as the free-field vibrations induced by road traffic [1-3], the ground-borne vibrations from metro tunnels [4-7] or induced by railway trains [8-11]. European projects such as CONVURT [12] or SUPERTRACK [13] reflect this increasing interest for these problematics.

In order to study and then to reduce these disturbances, efficient numerical prediction tools have to be developed and should have the possibility to consider any transportation system. Due to the geometry of the domain, the type of load acting on the transport structure and the necessity to take into account the soil-structure interaction [14], three-dimensional (3D) models of the structure and the surrounding soil are required. Nevertheless, theoretical and numerical difficulties have been encountered when using the usual 3D models for such large systems.

In this paper, a general model is proposed for which these domains are assumed to be periodic along one direction. Taking advantage of this geometrical property, the analysis for the overall soil-structure system can be restricted to one posed in a generic (or reference) cell [16]. For this, the Floquet decomposition [15] is used. The problem in the reference cell is then solved with a subdomain technique coupling a boundary element (BE) method for the soil and a finite element (FE) formulation for the structure $[17,18]$.

A general overview of this approach is given here and the first objective of this paper is to illustrate the versatility of the proposed method. Consequently, different structures are considered: a ballasted railway track partially embedded in a soft embankment layer and a tunnel located at a shallow depth (corresponding to the metro tunnel on the 
RER line at Paris). Moreover, comparative studies between the different structures have been carried out. At first a numerical comparative study is presented for one decisive parameter of the periodic model, that is the number of cells. Then the present method has been improved by introducing a general numerical rule called Floquet-Shannon criterion. Finally, for the physical aspects, the propagation of the periodic modes has been investigated which allows for a global view of the significant dynamical phenomena occurring in the soil-structure system, and then offers a first description of the common features (or the differences) for the behaviour of the two structures.

In the first section, the $3 \mathrm{D}$ soil-structure model is presented. The periodic model is described and the subdomain method used to solve the dynamic soil-structure interaction problem is briefly recalled. The second section is devoted to a comparative study between the different structures. From the numerical point of view, convergence analyses have been carried out to obtain the optimal number of cells and a simple general rule is proposed as an alternative. From the physical point of view, the propagation of the periodic modes along the structure is analysed.

\section{Soil-structure model}

In this section, the 3D model for the soil-structure system is presented. This model is based on a geometrical periodic formulation. Floquet decomposition is then introduced and the generic problem is presented. Moreover, the dynamic soil-structure interaction is taken into account using a subdomain method for which the structure is modeled with finite elements while the boundary element method is used for the soil.

\subsection{Periodic model}

\subsubsection{Definitions and notations}

A transportation track interacting with the soil is considered. This system is modeled by an unbounded structure with elastic properties, partially or totally embedded in a stratified visco-elastic half-space. This 3D domain, denoted by $\Omega$, is assumed to be periodic in the direction $\mathbf{e}_{\mathbf{y}}$ with $\left(\mathbf{e}_{\mathbf{x}}, \mathbf{e}_{\mathbf{y}}, \mathbf{e}_{\mathbf{z}}\right)$ a Cartesian reference system (see Fig. 1 in which a periodic soil-track system is represented). The length period is denoted by $L$.

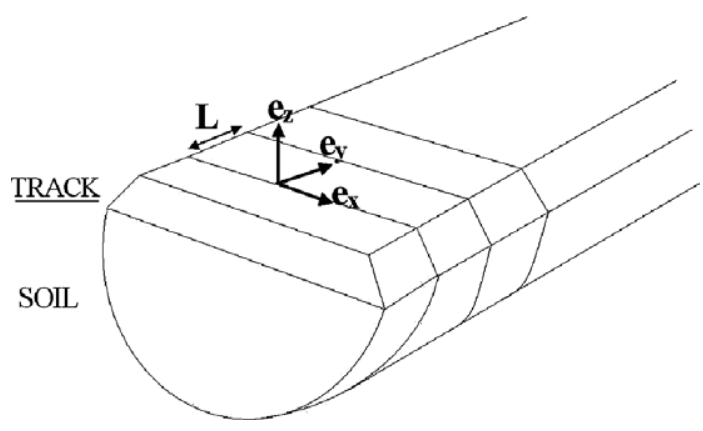

Fig. 1. Periodic soil-track system $\Omega$.

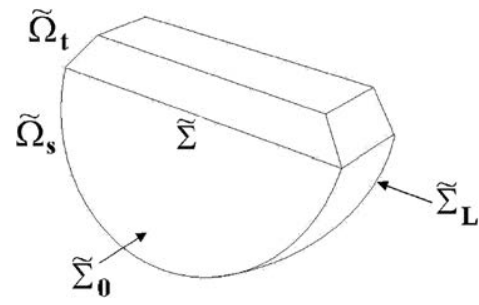

Fig. 2. Generic cell $\widetilde{\Omega}$.

The periodic domain $\Omega$ is constituted of a sequence of the same cell named the generic (or reference) cell $\widetilde{\Omega}$ defined by $\widetilde{\Omega}=\left\{\mathbf{x} \in \Omega \mid 0<\mathbf{x} \cdot \mathbf{e}_{\mathbf{y}}<L\right\}$ with $\mathbf{x}=(x, y, z)$ (see Fig. 2). This generic domain is such as $\widetilde{\Omega}=\widetilde{\Omega}_{\mathrm{t}} \cup \widetilde{\Omega}_{\mathrm{s}}$, where $\widetilde{\Omega}_{\mathrm{t}}$ corresponds to the bounded part related to the track structure and $\widetilde{\Omega}_{\mathrm{S}}$ is the unbounded soil domain in this generic cell.

The boundary $\partial \widetilde{\Omega}$ of $\widetilde{\Omega}$ can be decomposed as $\partial \widetilde{\Omega}=\widetilde{\Gamma}_{f} \cup \widetilde{\Gamma}_{\infty} \cup \widetilde{\Sigma}_{0} \cup \widetilde{\Sigma}_{L}$ with $\widetilde{\Gamma}_{f}$ the part where the Neumann boundary conditions are specified, $\widetilde{\Sigma}_{0}$ and $\widetilde{\Sigma}_{L}$ are the boundaries defined by $\widetilde{\Sigma}_{0}=\left\{\mathbf{x} \in \Omega \mid \mathbf{x} \cdot \mathbf{e}_{\mathbf{y}}=0\right\}$ and $\widetilde{\Sigma}_{L}=$ $\left\{\mathbf{x} \in \Omega \mid \mathbf{x} \cdot \mathbf{e}_{\mathbf{y}}=L\right\} \quad$ (see Fig. 2). Sommeferld's radiation conditions hold on $\widetilde{\Gamma}_{\infty}$. Finally, the position vector in the reference cell will be denoted by $\tilde{\mathbf{x}}=(\tilde{x}, \tilde{y}, \tilde{z})$.

The objective is to find the solution $\mathbf{u}$ of a boundary value problem in the domain $\Omega$ with applied loads $\mathbf{f}$. Taking advantage of the periodicity, it is shown $[15,16]$ that this problem can be substituted by one (the generic problem, see Section 2.1.2) in the domain $\widetilde{\Omega}$ with applied loads $\tilde{\mathbf{f}}$ and for which the solution $\tilde{\mathbf{u}}$ satisfies additional conditions on the boundary of the cell

$\tilde{\mathbf{u}}(\tilde{\mathbf{x}})=\mathrm{e}^{-i \kappa L} \tilde{\mathbf{u}}\left(\tilde{\mathbf{x}}-L \mathbf{e}_{\mathbf{y}}\right) \quad$ on $\widetilde{\Sigma}_{L}$

for any wavenumber $\kappa \in]-\pi / L, \pi / L[$. The solution $\tilde{\mathbf{u}}$ is called the Floquet transform [15] of $\mathbf{u}$ defined by

$\tilde{\mathbf{u}}(\tilde{\mathbf{x}}, \kappa)=\sum_{n=-\infty}^{+\infty} \mathbf{u}\left(\tilde{\mathbf{x}}+n L \mathbf{e}_{\mathbf{y}}\right) \mathrm{e}^{i n \kappa L}$.

Moreover, for any position in $\Omega$, the solution $\mathbf{u}$ can be recovered from $\tilde{\mathbf{u}}$ using the inverse Floquet transform defined by

$\mathbf{u}\left(\tilde{\mathbf{x}}+n L \mathbf{e}_{\mathbf{y}}\right)=\frac{L}{2 \pi} \int_{-\pi / L}^{\pi / L} \tilde{\mathbf{u}}(\tilde{\mathbf{x}}, \kappa) \mathrm{e}^{-i n \kappa L} \mathrm{~d} \kappa$.

Finally, it should be remarked that $\tilde{\mathbf{u}}$ can be built from the Fourier transform of $\mathbf{u}$ (along $\mathbf{e}_{\mathbf{y}}$ ) denoted by $\hat{\mathbf{u}}$, using the following formula:

$\tilde{\mathbf{u}}(\tilde{\mathbf{x}}, \kappa)=\sum_{n=-\infty}^{+\infty} \hat{\mathbf{u}}\left(\kappa+\frac{2 n \pi}{L}\right) \mathrm{e}^{-i\left(\kappa+\frac{2 n \pi}{L}\right) \tilde{y}}$,

$\hat{\mathbf{u}}\left(k_{y}\right)=\frac{1}{L} \int_{0}^{L} \tilde{\mathbf{u}}(\tilde{y}, \kappa) \mathrm{e}^{i k_{y} \tilde{y}} \mathrm{~d} \tilde{y}, \quad k_{y}=\kappa+2 n \pi / L$.

\subsubsection{Generic problem of the $3 D$ periodic soil-structure system}

Using the previous results and the defined notations, the following generic problem has to be solved: for every 
$\kappa \in]-\pi / L, \pi / L[$ and for every circular frequency $\omega$ in the band of analysis, the structure displacement $\tilde{\mathbf{u}}_{\mathrm{t}}$ in $\widetilde{\Omega}_{\mathrm{t}}$ and the soil displacement $\tilde{\mathbf{u}}_{\mathrm{s}}$ in $\widetilde{\Omega}_{\mathrm{s}}$ have to satisfy

$\operatorname{div} \boldsymbol{\sigma}_{\beta}\left(\tilde{\mathbf{u}}_{\beta}\right)=-\rho_{\beta} \omega^{2} \tilde{\mathbf{u}}_{\beta} \quad$ in $\widetilde{\Omega}_{\beta}, \quad \beta \in\{\mathrm{t}, \mathrm{s}\}$,

$\mathbf{t}_{\mathrm{t}}\left(\tilde{\mathbf{u}}_{\mathrm{t}}\right)=\tilde{\mathbf{f}}_{\mathrm{t}}$ on $\widetilde{\Gamma}_{f \mathrm{t}}$,

$\mathbf{t}_{\mathrm{s}}\left(\tilde{\mathbf{u}}_{\mathrm{s}}\right)=\mathbf{0}$ on $\widetilde{\Gamma}_{f \mathrm{~s}}$,

$\tilde{\mathbf{u}}_{\beta}(\tilde{\mathbf{x}})=\mathrm{e}^{-i \kappa L} \tilde{\mathbf{u}}_{\beta}\left(\tilde{\mathbf{x}}-L \mathbf{e}_{\mathbf{y}}\right) \quad$ on $\widetilde{\Sigma}_{L \beta}, \quad \beta \in\{\mathrm{t}, \mathrm{s}\}$,

in which $\rho_{\beta}(\beta \in\{\mathrm{t}, \mathrm{s}\})$ is the mass density, $\boldsymbol{\sigma}_{\beta}\left(\mathbf{u}_{\beta}\right)$ is the elastic stress tensor associated to the displacement field $\mathbf{u}_{\beta}$ and $\mathbf{t}_{\beta}\left(\mathbf{u}_{\beta}\right)=\boldsymbol{\sigma}_{\beta}\left(\mathbf{u}_{\beta}\right) \mathbf{n}$ corresponds to the traction vector on the considered boundary using the outer normal convention for $\mathbf{n}$. Finally, the following coupling equations have to be satisfied:

$\tilde{\mathbf{u}}_{\mathrm{t}}=\tilde{\mathbf{u}}_{\mathrm{s}}$ on $\widetilde{\Sigma}$,

$\mathbf{t}_{\mathrm{t}}\left(\tilde{\mathbf{u}}_{\mathrm{t}}\right)+\mathbf{t}_{\mathrm{s}}\left(\tilde{\mathbf{u}}_{\mathrm{s}}\right)=\mathbf{0}, \quad$ on $\widetilde{\Sigma}$,

where $\widetilde{\Sigma}$ is the interface between the structure and the soil in the generic cell (see Fig. 2).

Once the generic problem defined by Eqs. (6)-(11) has been solved, the displacement for any $\mathbf{x} \in \Omega$ can be recovered by using the inverse Floquet transform defined by Eq. (3). The solution of the generic problem is now concerned. In the following, a subdomain approach is proposed to solve this problem.

\subsection{Subdomain model}

The 3D domain considered (the generic cell) is decomposed into two subdomains (the structure and the soil). In this manner, each subdomain can be independently modeled. The structure is modeled using the finite element method and its dynamical behaviour is characterized by periodic modes while the boundary element method with suitable Green functions is used for the soil. In the next, this method $[17,18]$ is presented.

The displacement field $\tilde{\mathbf{u}}_{\mathrm{t}}$ in the bounded generic structure is decomposed on a given basis of modes $\left\{\boldsymbol{\Psi}_{k}\right\}_{k=1, \ldots, N}$ which have to satisfy Eq. (1). This kinematic basis can be built as follows [7]:

$\left.\boldsymbol{\Psi}_{k}(\tilde{\mathbf{x}}, \kappa)=\mathrm{e}^{-i \kappa \tilde{\mathbf{x}} \cdot \mathbf{e}_{\mathbf{y}}} \boldsymbol{\Phi}_{k}(\tilde{\mathbf{x}}), \quad \kappa \in\right]-\pi / L, \pi / L[$,

where $\left\{\boldsymbol{\Phi}_{k}\right\}_{k=1, \ldots, N}$ are the periodic modes, solutions of the generalized eigenvalue problem associated to the generic structure and satisfying

$\boldsymbol{\Phi}_{k}(\tilde{\mathbf{x}})=\boldsymbol{\Phi}_{k}\left(\tilde{\mathbf{x}}-L \mathbf{e}_{\mathbf{y}}\right), \quad \forall \tilde{\mathbf{x}} \in \widetilde{\Sigma}_{L t}$.

Then, for any $\omega$, the displacement field in the generic structure is written as

$\tilde{\mathbf{u}}_{\mathbf{t}}(\tilde{\mathbf{x}}, \kappa, \omega)=\sum_{k=1}^{N} \boldsymbol{\Psi}_{k}(\tilde{\mathbf{x}}, \kappa) c_{k}(\kappa, \omega)$

with $\left\{c_{k}\right\}_{k=1, \ldots, N}$ the generalized degrees of freedom. Moreover, the soil displacement in the generic cell is written as $\tilde{\mathbf{u}}_{\mathrm{s}}(\tilde{\mathbf{x}}, \kappa, \omega)=\sum_{k=1}^{N} \tilde{\mathbf{u}}_{d k}(\tilde{\mathbf{x}}, \kappa, \omega) c_{k}(\kappa, \omega)$,

where $\left\{\tilde{\mathbf{u}}_{d k}\right\}_{k=1, \ldots, N}$ are elastodynamic fields satisfying

$\tilde{\mathbf{u}}_{d k}=\boldsymbol{\Psi}_{k}$, on $\widetilde{\Sigma}$.

Using a standard Galerkin procedure for the balance of momentum in the generic cell, for any $\boldsymbol{\Psi}_{k}$ in the basis, the following linear system is obtained:

$\left[\mathbf{K}_{\mathrm{t}}(\kappa)-\omega^{2} \mathbf{M}_{\mathrm{t}}(\kappa)+\mathbf{K}_{\mathrm{s}}(\kappa, \omega)\right] \mathbf{c}(\kappa, \omega)=\mathbf{F}_{\mathrm{t}}(\kappa, \omega)$

with $\mathbf{c}=\left(c_{1}, \ldots, c_{N}\right)$ the vector of generalized degrees of freedom. The reduced stiffness and mass matrices of the structure, $\left[\mathbf{K}_{\mathrm{t}}\right]$ and $\left[\mathbf{M}_{\mathrm{t}}\right]$, are defined by

$$
\begin{aligned}
& {\left[\mathbf{K}_{\mathrm{t}}\right]_{k l}=\int_{\widetilde{\Omega}_{\mathrm{t}}} \boldsymbol{\sigma}_{\mathrm{t}}\left(\boldsymbol{\Psi}_{k}\right): \boldsymbol{\epsilon}\left(\overline{\mathbf{\Psi}}_{l}\right) \mathrm{d} V,} \\
& {\left[\mathbf{M}_{\mathrm{t}}\right]_{k l}=\int_{\widetilde{\Omega}_{\mathrm{t}}} \rho_{\mathrm{t}} \boldsymbol{\Psi}_{k} \cdot \overline{\boldsymbol{\Psi}}_{l} \mathrm{~d} V,}
\end{aligned}
$$

where $\epsilon(\mathbf{u})$ is the strain tensor associated to the displacement field $\mathbf{u}$. The quantity $\overline{\mathbf{u}}$ is the conjugate of $\mathbf{u}$ and $\mathbf{A}: \mathbf{B}=\sum_{k l} A_{k l} B_{k l}$ is the contraction of the two tensors $\mathbf{A}$ and $\mathbf{B}$. In the context of a structure modeled by the finite element method, these matrices can be written as

$\left[\mathbf{K}_{\mathrm{t}}\right]=[\boldsymbol{\Psi}]^{*}\left[K_{\mathrm{t}}\right][\boldsymbol{\Psi}]$,

$\left[\mathbf{M}_{\mathrm{t}}\right]=[\boldsymbol{\Psi}]^{*}\left[M_{\mathrm{t}}\right][\boldsymbol{\Psi}]$,

in which $[\Psi]$ is the matrix containing the modes $\left\{\boldsymbol{\Psi}_{k}\right\}_{k=1, \ldots, N}$ and where $\left[K_{\mathrm{t}}\right]$ and $\left[M_{\mathrm{t}}\right]$ correspond, respectively, to the finite element stiffness and mass matrices. The superscript $*$ denotes the adjoint of matrices.

The generalized force vector $\mathbf{F}_{t}$, related to the forces $\tilde{\mathbf{f}}_{t}$ acting on the structure, is defined by

$\left[\mathbf{F}_{\mathrm{t}}\right]_{k}=\int_{\widetilde{\Gamma}_{f \mathrm{t}}} \tilde{\mathbf{f}}_{\mathrm{t}} \cdot \overline{\mathbf{\Psi}}_{k} \mathrm{~d} S$.

Finally, the soil impedance matrix $\left[\mathbf{K}_{\mathrm{s}}\right]$ is defined by

$\left[\mathbf{K}_{\mathrm{s}}\right]_{k l}=\int_{\widetilde{\Sigma}} \mathbf{t}_{\mathrm{s}}\left(\tilde{\mathbf{u}}_{d k}\right) \cdot \overline{\mathbf{\Psi}}_{l} \mathrm{~d} S$,

where $\mathbf{t}_{\mathbf{s}}\left(\tilde{\mathbf{u}}_{d k}\right)$ is the traction field related to the elastodynamic field $\tilde{\mathbf{u}}_{d k}$ defined by Eqs. (15) and (16). The procedure to get Eq. (23) and its calculation are subject to difficulties since integrals along unbounded surfaces of the generic cell have been encountered. Then, the standard boundary integral equation cannot be used directly for the soil part, because the left and the right periodic interfaces $\widetilde{\Sigma}_{0}$ and $\widetilde{\Sigma}_{L}$ are not bounded. However, in the context of boundary integral equation, surfaces where the Green's functions satisfy the imposed boundary conditions disappear from the final equation (since the fields will automatically satisfy them). Then in order to deal with integral equation on a bounded surface (that is $\widetilde{\Sigma}$, as it can be seen in Eq. (23)), Green's functions satisfying the periodic boundary conditions have been proposed [16] and are referred to the Green-Floquet functions defined by 
$\tilde{\mathbf{u}}^{G}(\tilde{\mathbf{x}}, \tilde{\mathbf{y}}, \kappa)=\sum_{n=-\infty}^{+\infty} \mathbf{u}^{G}\left(\tilde{\mathbf{x}}, \tilde{\mathbf{y}}+n L \mathbf{e}_{\mathbf{y}}\right) \mathrm{e}^{i n \kappa L}$,

where $\mathbf{u}^{G}(\mathbf{x}, \mathbf{y})$ is the Green function at the point $\mathbf{x}$ due to a point force at $\mathbf{y}$. Other advantage of Eq. (24) is that the Green-Floquet function has the same singularities as the original Green function. Then, same numerical integration methods can be used.

\section{Numerical examples and comparative studies}

Different structures, partially or totally embedded in soil, are considered here: a ballasted railway track and a tunnel located at a shallow depth. By means of a comparative study, this section aims at obtaining a general rule concerning the determination of the optimal number of cells and at analysing the wave propagation pattern along these structures by using a suitable tool.

In the first subsection, the geometrical and mechanical characteristics of each structure (and the surrounding soil) are described. From the numerical point of view (Section 3.2 ), convergence analyses have been performed to update one parameter of the periodic model, that is the number of cells. Based on the convergence results, a general rule is proposed to obtain the optimal number of cells. Finally, in the last subsection devoted to the physical point of view, the propagation of the periodic modes along the structures is studied.

\subsection{Description of the soil-structure domains}

In this subsection, the geometrical and mechanical properties of the soil-structure system are presented. The structure is modeled with finite elements whereas the soil is considered using a boundary element method. It should be noted here that the finite element models are built using the structural dynamics toolbox in MATLAB, and the soil impedance matrix defined by Eq. (23) is computed using the Miss3D software $[17,18]$.

\subsubsection{Ballasted railway track}

3.1.1.1. Track-structure model in the generic cell. The model of the overall railway track is generated from a generic cell whose length along the periodicity direction $\mathbf{e}_{\mathbf{y}}$ is equal to $L=0.6 \mathrm{~m}$ (see the FE model of this cell in Fig. 3).

The generic railway track cell is composed of two layers. The first one, with a thickness of $0.67 \mathrm{~m}$, models a layer of ballast with the following mechanical properties: Young's modulus $E=2 \times 10^{8} \mathrm{~N} / \mathrm{m}^{2}$, Poisson's ratio $v=0.35$ and mass density $\rho=2100 \mathrm{~kg} / \mathrm{m}^{3}$. The second one models a layer made up of sand and gravels $\left(E=1.8 \times 10^{8} \mathrm{~N} / \mathrm{m}^{2}\right.$, $v=0.35$ and $\rho=2135 \mathrm{~kg} / \mathrm{m}^{3}$ ). On this generic track-structure, two bi-bloc sleepers in concrete $\left(E=3 \times 10^{10} \mathrm{~N} / \mathrm{m}^{2}\right.$, $v=0.25$ and $\rho=2200 \mathrm{~kg} / \mathrm{m}^{3}$ ) are taken into account and are connected in pairs by means of steely crossbars $\left(E=2.1 \times 10^{11} \mathrm{~N} / \mathrm{m}^{2}, \quad v=0.285\right.$ and $\left.\rho=7800 \mathrm{~kg} / \mathrm{m}^{3}\right)$. Moreover, rails (with the same mechanical properties as

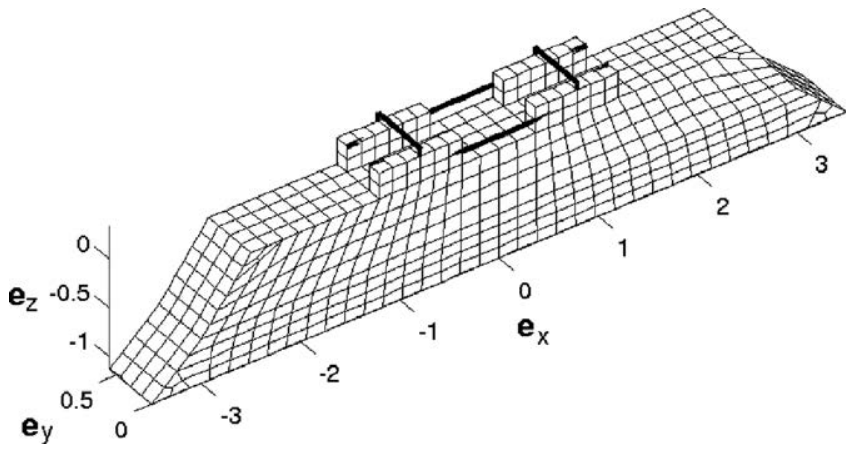

Fig. 3. Finite element model of the generic track cell.

the crossbars) have been modeled and are connected to the sleepers with pads (with a vertical stiffness equal to $159 \times 10^{6} \mathrm{~N} / \mathrm{m}$ ).

The FE model of the generic cell is built using 8-node isoparametric brick elements and standard beam elements (for the rails and crossbars). The mesh is then constituted of 1140 elements with 1693 nodes. The BE mesh, which is associated to the soil-structure interface, is composed of 144 elements.

3.1.1.2. Soil model in the generic cell. The soil is assumed to be a stratified visco-elastic half-space: the first layer, with a thickness of $4.5 \mathrm{~m}$, represents an embankment with a shear and a dilatational wave velocities equal, respectively, to $C_{s}=67 \mathrm{~m} / \mathrm{s}$ and $C_{p}=125 \mathrm{~m} / \mathrm{s}$. This embankment rests on a half-space made of a stiffer material $\left(C_{s}=315 \mathrm{~m} / \mathrm{s}\right.$ and $C_{p}=772 \mathrm{~m} / \mathrm{s}$ ). A mass density $\rho=1720 \mathrm{~kg} / \mathrm{m}^{3}$ and a hysteretic damping ratio $\beta=5 \%$ are considered for the overall soil domain.

\subsubsection{Shallow tunnel}

The structure considered is the tunnel on the RER B line at Cité Universitaire site in Paris. The top of the tunnel is $2.3 \mathrm{~m}$ below the ground surface.

3.1.2.1. Tunnel-structure model in the generic cell. The tunnel is a masonry cut-and-over one. Its width equals $11.9 \mathrm{~m}$ (see Fig. 4). The tunnel thickness is $0.6 \mathrm{~m}$ on the top and $1.5 \mathrm{~m}$ on the two sides.

Taking into account these properties, a periodic model for the tunnel is built, based on a generic cell whose length along $\mathbf{e}_{\mathbf{y}}$ equals $L=0.6 \mathrm{~m}$ (see the $\mathrm{FE}$ model of this cell in Fig. 5). The characteristics of the masonry are $E=$ $1.4 \times 10^{10} \mathrm{~N} / \mathrm{m}^{2}, v=0.15$ and $\rho=2400 \mathrm{~kg} / \mathrm{m}^{3}$.

The FE model of the cell is generated using 8-node isoparametric brick elements. The mesh has 408 elements with 741 nodes. The BE mesh is constituted of 140 elements.

3.1.2.2. Soil model in the generic cell. The soil is modeled as a stratified visco-elastic half-space whose stratigraphy has been determined by means of SASW tests [19]. The first layer and the second layer, with a thickness of $1.4 \mathrm{~m}$ and $2.8 \mathrm{~m}$, respectively, have the following properties: 


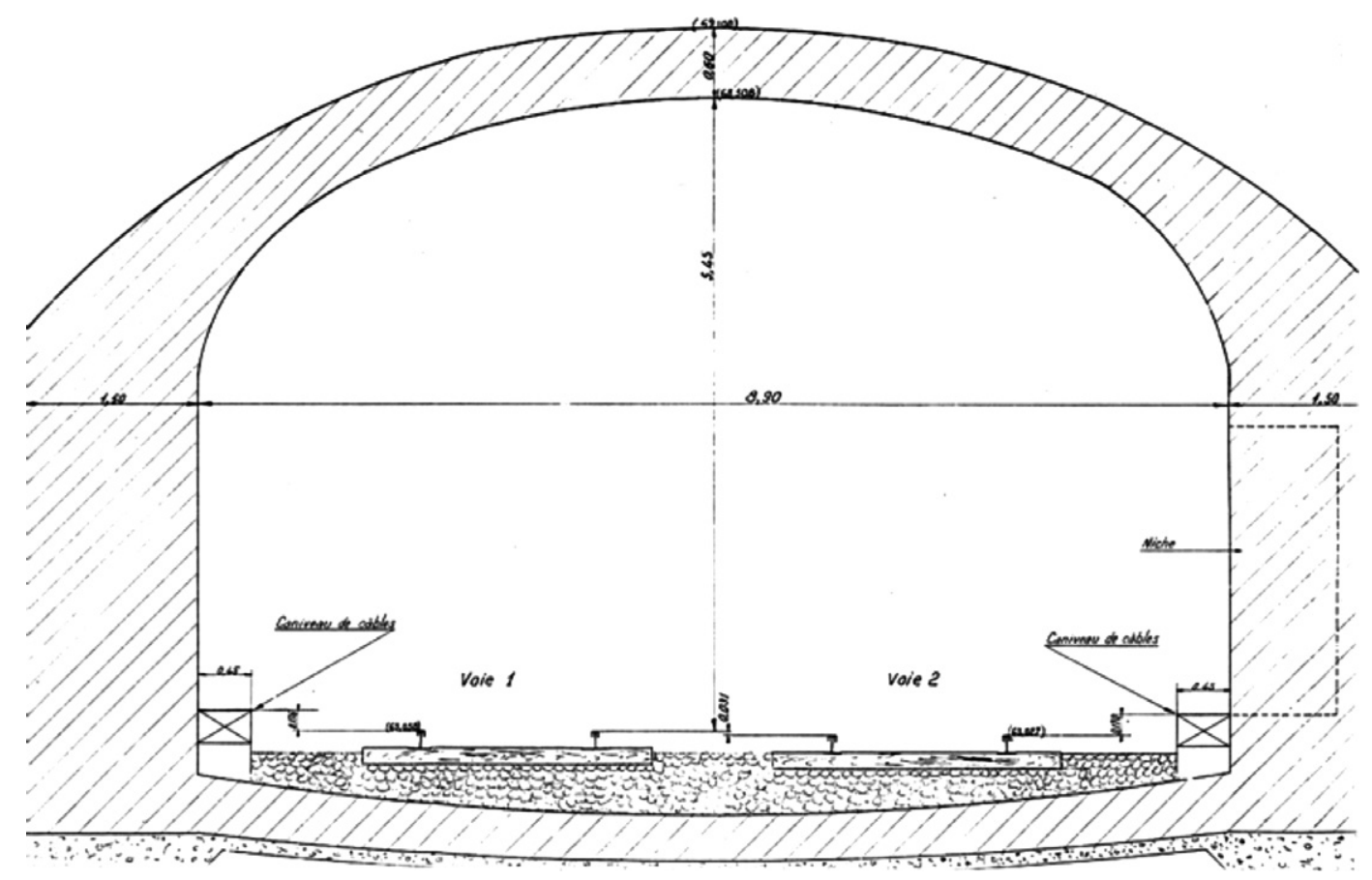

Fig. 4. Cross-section of the tunnel on the RER B line at Cité Universitaire.

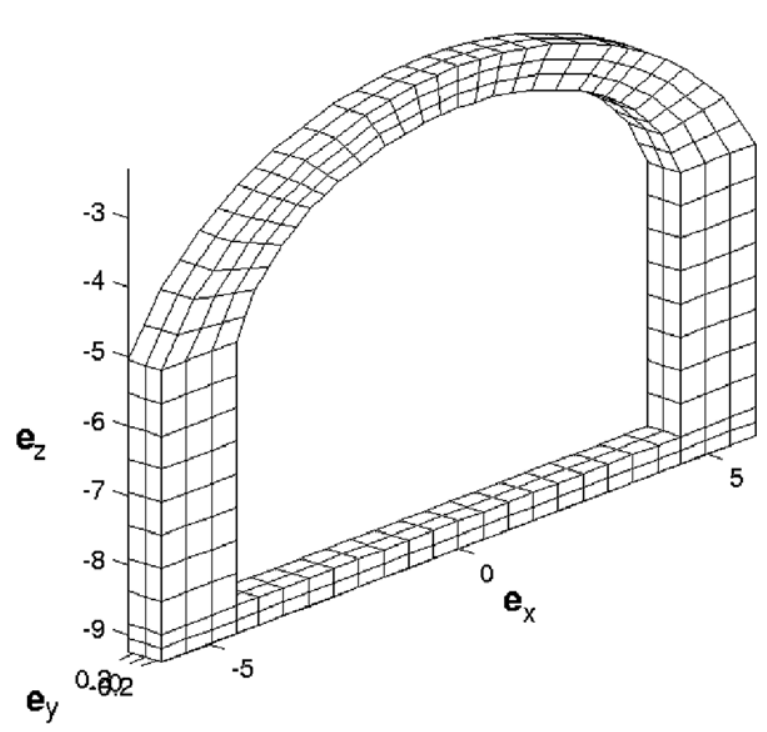

Fig. 5. Finite element model of the generic tunnel cell.

$C_{s_{1}}=115 \mathrm{~m} / \mathrm{s}, C_{p_{1}}=282 \mathrm{~m} / \mathrm{s}$ and $C_{s_{2}}=220 \mathrm{~m} / \mathrm{s}, C_{p_{2}}=$ $539 \mathrm{~m} / \mathrm{s}$. The last layer models an homogeneous half-space $\left(C_{s}=335 \mathrm{~m} / \mathrm{s}, C_{p}=772 \mathrm{~m} / \mathrm{s}\right)$. For all materials, the mass density is equal to $1700 \mathrm{~kg} / \mathrm{m}^{3}$ and a hysteretic damping ratio of $5 \%$ is assumed.

\subsection{Numerical comparative study}

This subsection is devoted to the determination of the optimal value for the parameters of the periodic model. Two main parameters control this model: the number of structural modes $N$ (see Eq. (14)) and the number of cells (see Eq. (24)). In this subsection, only the analysis related to the number of cells is addressed, since this parameter is considered as the most specific of the model (and the determination of the optimal number of modes corresponds to an usual study of structural dynamics). At first, a convergence analysis, using a norm of the soil impedance, has been performed to obtain the optimal number of cells. Then, a simple numerical rule, called the Floquet-Shannon criterion, is proposed.

\subsubsection{Convergence analysis using a norm of the soil impedance}

Taking into account Eq. (24), the numerical computation can be performed only for a finite series where $n=-\bar{N}_{y}, \ldots, \bar{N}_{y}$ and $\left|\bar{N}_{y}\right|<\infty$. In this case, the total number of cells considered is $N_{y}^{\mathrm{tot}}=2 \times \bar{N}_{y}+1$.

Concerning the first structure, that is the ballasted railway track, a convergence analysis with respect to the number of cells for the frequency band $B=2 \pi \times[1,80] \mathrm{rad} / \mathrm{s}$ has been carried out. A norm associated to the soil impedance $\left[\mathbf{K}_{\mathrm{s}}\right]$ is introduced and is defined by

$\left\|\mid\left[\mathbf{K}_{\mathrm{s}}\right]\right\|\left\|_{B}^{2}=\int_{B}\right\|\left[\mid \mathbf{K}_{\mathrm{s}}(\omega)\right]\|\|^{2} \mathrm{~d} \omega$

with

$\left\|\left[\mathbf{K}_{\mathrm{s}}(\omega)\right]\right\| \|^{2}=\operatorname{Tr}\left(\left[\mathbf{K}_{\mathrm{s}}(\omega)\right]\left[\mathbf{K}_{\mathrm{s}}(\omega)\right]^{*}\right), \quad \forall \omega \in B$,

in which $\operatorname{Tr}$ denotes the trace of matrices and where the superscript $*$ corresponds to the adjoint of matrices. On Fig. 6, it can be seen that a good convergence is obtained for a total number of cells $N_{y}^{\text {tot }} \simeq 140$ cells.

Concerning the shallow tunnel, it is found that a number of cells equal to 160 is sufficient to obtain a good convergence. 


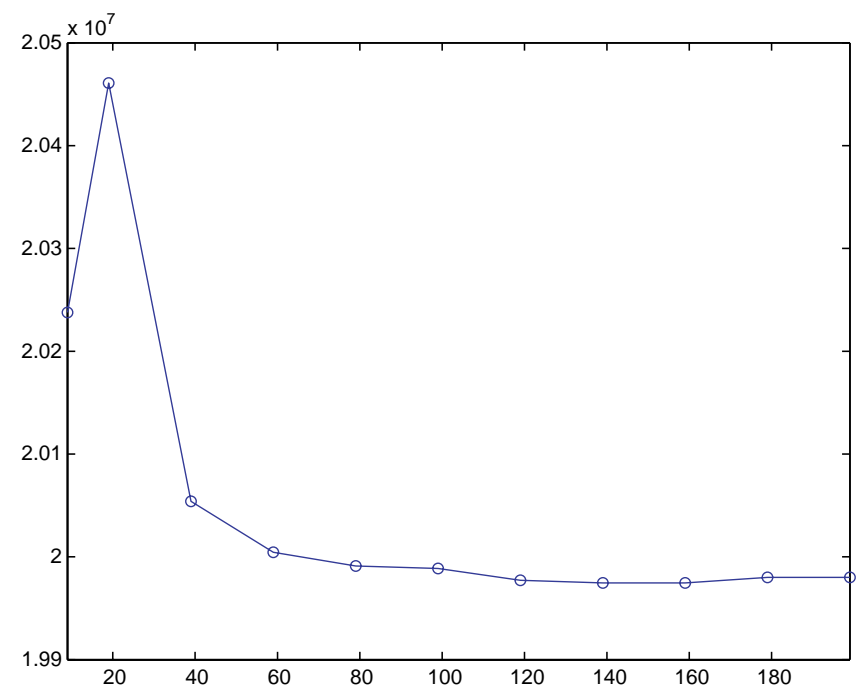

Fig. 6. Convergence with respect to the number of cells. Graph of $N_{y}^{\mathrm{tot}} \mapsto\left\|||\left[\mathbf{K}_{\mathrm{s}}\right] \mid\right\|_{B}$.

It can be noted here that the optimal number of cells for the two cases is of the same order, even if the mechanical and geometrical properties are totally different (only the length in the periodicity direction of the generic cell for these two structures remains the same, equal to $0.6 \mathrm{~m}$ ). Based on these observations, one can think of the possibility to define a general rule for the determination of the number of cells, and then to avoid the previous convergence analyses which require an important numerical effort and are often time-consuming. The next subsection aims to define this formula.

\subsubsection{Floquet-Shannon criterion}

The convergence analyses described previously allow to get a finite number $N_{y}^{\text {tot }}$ of cells. Then, a length along the periodicity direction, beyond which the contribution of the studied quantity (for instance the displacement) is negligible, may be looked for. Consequently, in this subsection, we consider a bounded displacement-function with a support in $\left[0, N_{y}^{\text {tot }} L\right]$ along the periodicity direction. This displacement-function is reproduced by translation along the $\mathbf{e}_{\mathbf{y}}$ axis. This new function (named $\mathbf{u}$ by convenience) is then periodic and its Fourier transform (along $\mathbf{e}_{\mathbf{y}}$ ) can be written as

$\left.\hat{\mathbf{u}}\left(k_{y}\right)=\sum_{j=-\infty}^{+\infty} \boldsymbol{\alpha}_{j} \delta \quad k_{y}-\frac{2 \pi j}{N_{y}^{\mathrm{tot}} L}\right)$,

where $N_{y}^{\text {tot }}$ is the total number of cells considered. Taking into account Eqs. (4), (5) and (26), we deduce that the wavenumber $\kappa$ should verify

$\kappa=\frac{2 \pi j}{N_{y}^{\mathrm{tot}} L}-\frac{2 \pi n}{L}$.

Since $\kappa \in]-\pi / L, \pi / L\left[\right.$, we obtain that $j=j_{0}+n N_{y}^{\text {tot }}$ with $-\bar{N}_{y}<j_{0}<\bar{N}_{y}$, since $N_{y}^{\mathrm{tot}}=2 \times \bar{N}_{y}+1$. Introducing this expression in Eq. (27), we can deduce that the wavenumber step $\Delta \kappa$ is such that

$\Delta \kappa=\frac{2 \pi}{N_{y}^{\text {tot }} L}$.

From this equation, similar to the Shannon criterion in the Fourier domain, a new rule is obtained and it is named the Floquet-Shannon criterion. Here the parameter is not the number of cells (as seen in the previous subsection) but a maximal length. Then, for a given step $\Delta \kappa$, the FloquetShannon criterion defined by Eq. (28) says that the computation cannot be performed beyond a maximal length equal to $N_{y}^{\text {tot }} L=2 \pi / \Delta \kappa$. For a case in which 160 cells are chosen, the wavenumber step $\Delta \kappa \simeq 6 \times 10^{-2} \mathrm{rad} / \mathrm{m}$. In other words, if $\Delta \kappa=6 \times 10^{-2} \mathrm{rad} / \mathrm{m}$, the computation cannot be performed beyond a maximal length of $96 \mathrm{~m}$.

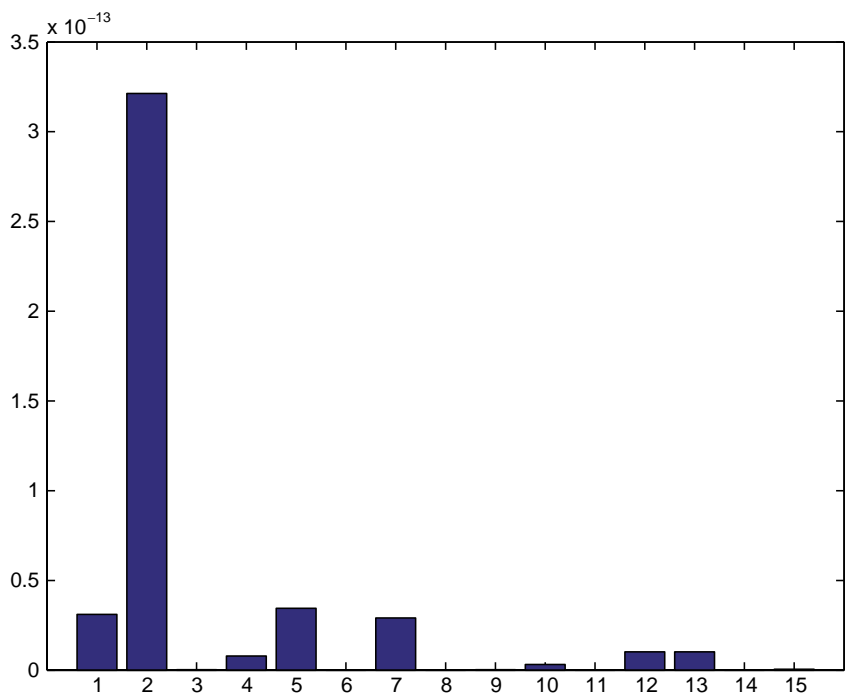

Fig. 7. $\left\|q_{k}^{0}\right\|_{B}^{2}$ with respect to the associated mode $k$.

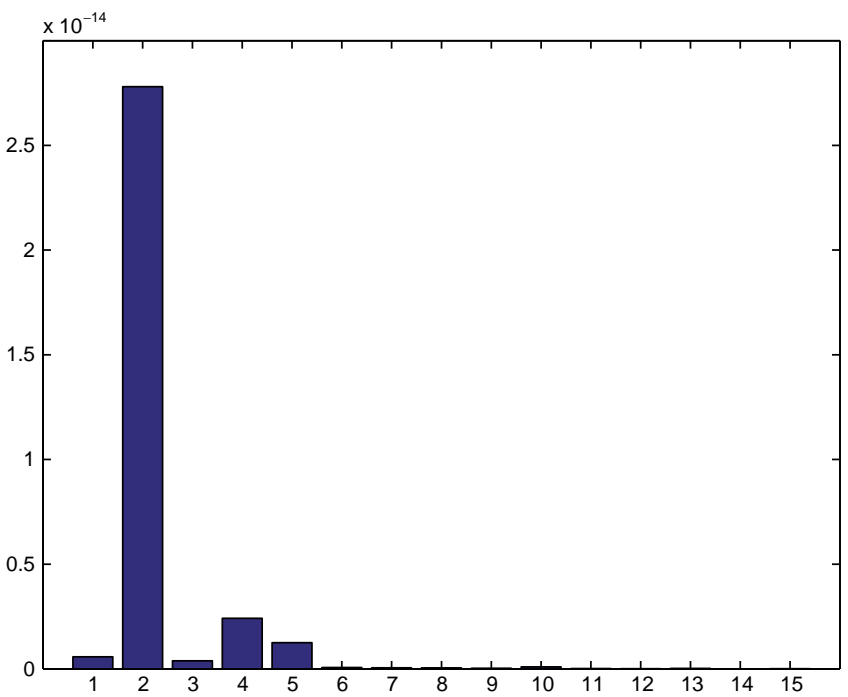

Fig. 8. $\left\|q_{k}^{40}\right\|_{B}^{2}$ with respect to the associated mode $k$. 


\subsection{Comparative study of the physical features}

In this subsection, the periodic modes propagation along the structure is investigated. This study allows to get a first seizing of the significant dynamical phenomena occurring in the soil-structure system. Then such an analysis gives a preliminary description of the common features (or differences) for the behaviour of the two structures.

\subsubsection{Informations on the periodic modes of the structures}

The periodic modes defined by Eq. (13) are considered. For the ballasted railway track, a number of 15 modes is considered (this value results from a convergence study). The first four modes correspond to the rigid body modes (the other two, corresponding to the rotations around $\mathbf{e}_{\mathbf{x}}$ and $\mathbf{e}_{\mathbf{z}}$ axes, do not satisfy the periodic condition defined

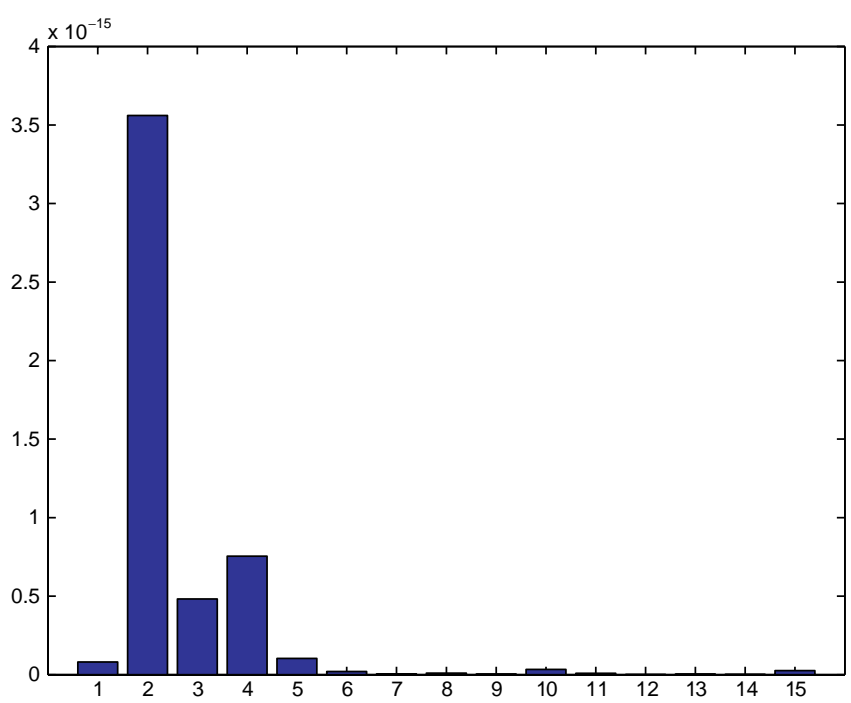

Fig. 9. $\left\|q_{k}^{80}\right\|_{B}^{2}$ with respect to the associated mode $k$.

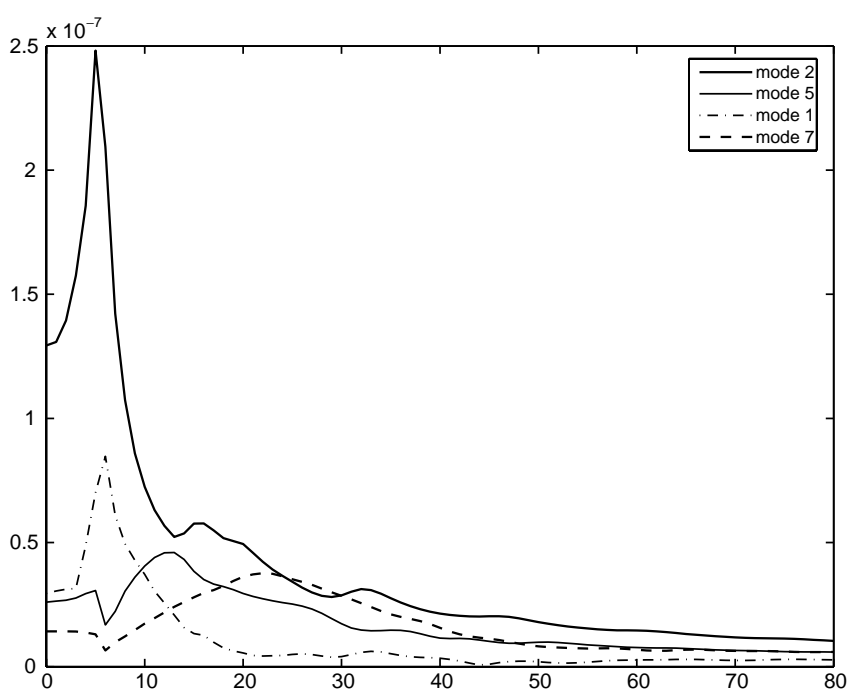

Fig. 10. Functions $f \mapsto\left|q_{k}^{0}(f)\right|$ for the modes $k=2,5,1$ and 7, with $f \in[0,80] \mathrm{Hz}$. by Eq. (13)). The eigenfrequency associated to the 5th mode is equal to $f_{5}=12.53 \mathrm{~Hz}$ and $f_{15}=69.59 \mathrm{~Hz}$ for the 15 th mode. Concerning the shallow tunnel, it is found that the group of the first 30 modes has to be taken into account $\left(f_{5}=9.9 \mathrm{~Hz}\right.$ and $\left.f_{30}=224.8 \mathrm{~Hz}\right)$.

\subsubsection{Propagation of the periodic modes}

For this study, the generalized coordinates associated to the periodic modes are used. Then, for any $\omega$ in the band of analysis $B$, the vector of generalized coordinates $\mathbf{q}^{j}$ related to the cell $j$, with $j=-\bar{N}_{y}, \ldots, \bar{N}_{y}(j=0$ refers to the generic cell), is defined by

$\mathbf{q}^{j}(\omega)=\left(q_{1}^{j}(\omega), \ldots, q_{N}^{j}(\omega)\right)$

with $\mathbf{U}^{j}(\omega)=[\boldsymbol{\Phi}] \mathbf{q}^{j}(\omega)$,

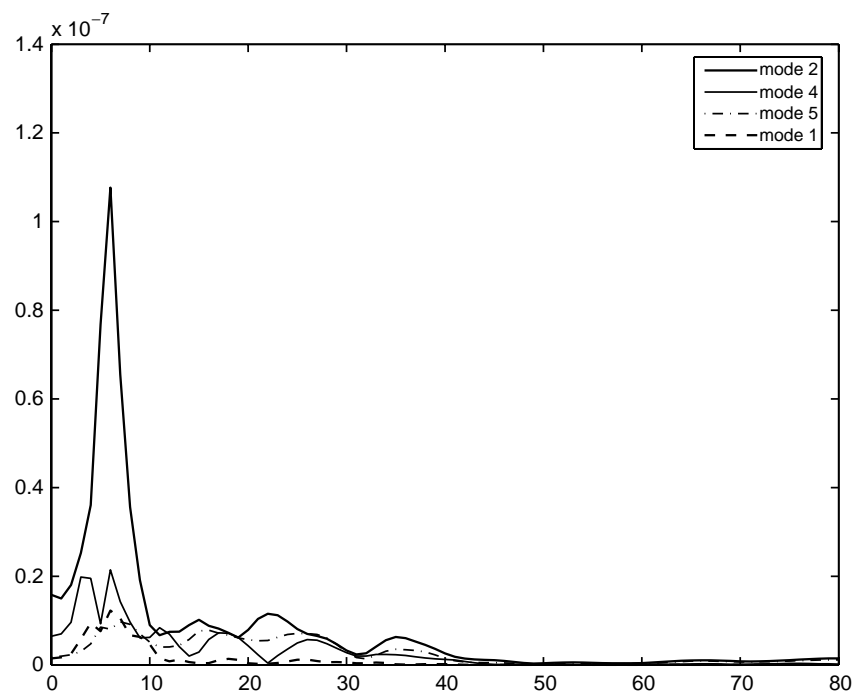

Fig. 11. Functions $f \mapsto\left|q_{k}^{40}(f)\right|$ for the modes $k=2,4,5$ and 1, with $f \in[0,80] \mathrm{Hz}$.

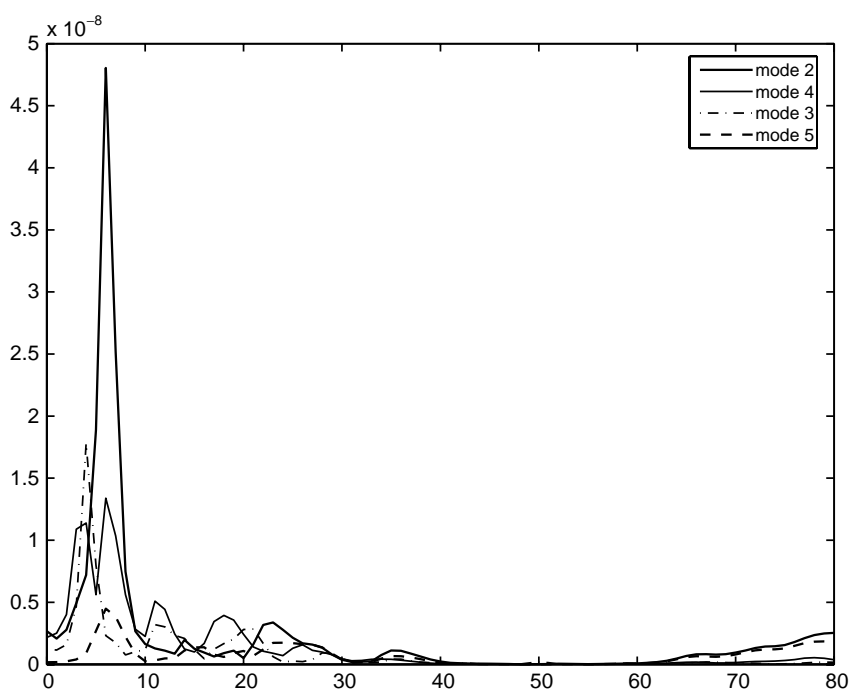

Fig. 12. Functions $f \mapsto\left|q_{k}^{80}(f)\right|$ for the modes $k=2,4,3$ and 5, with $f \in[0,80] \mathrm{Hz}$. 
in which $[\boldsymbol{\Phi}]$ is the FE matrix containing the $N$ periodic modes defined by Eq. (13) and where the FE vector $\mathbf{U}^{j}$ is the displacement-response of the structure-cell $j$ for an impulse force at a point belonging to the reference cell. It is worth to notice that the solution $\mathbf{U}^{j}$ is calculated using the method described in Section 2 (it should be precised here that a trapezoidal integration scheme is used for the inverse Floquet transform defined by Eq. (3)). For $k \in\{1, \ldots, N\}$, the quantity $q_{k}^{j}$ highlights the contribution of the $k$ th periodic mode in the displacement-response of the cell $j$.

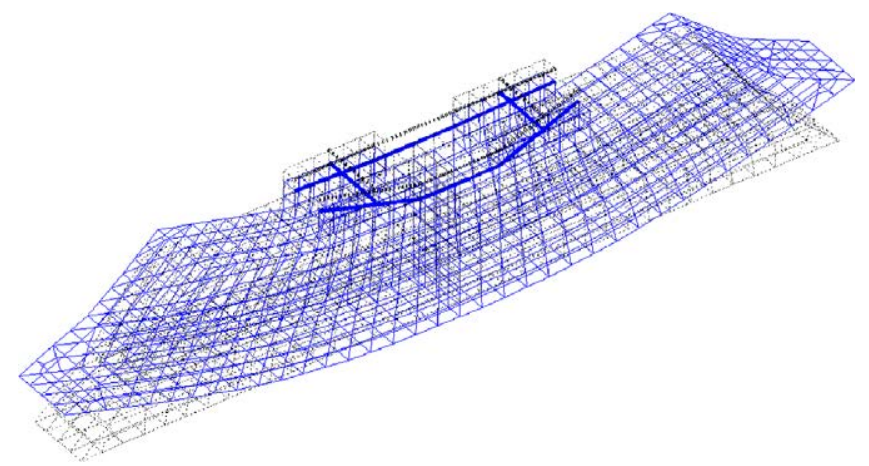

Fig. 13. Periodic mode no. 5.

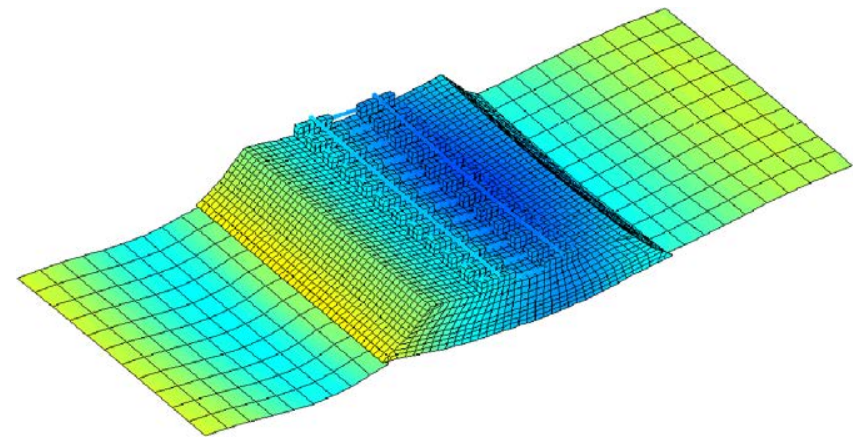

Fig. 14. Response-displacement at $10 \mathrm{~Hz}$ due to a sinusoidal force, at $t=0$.

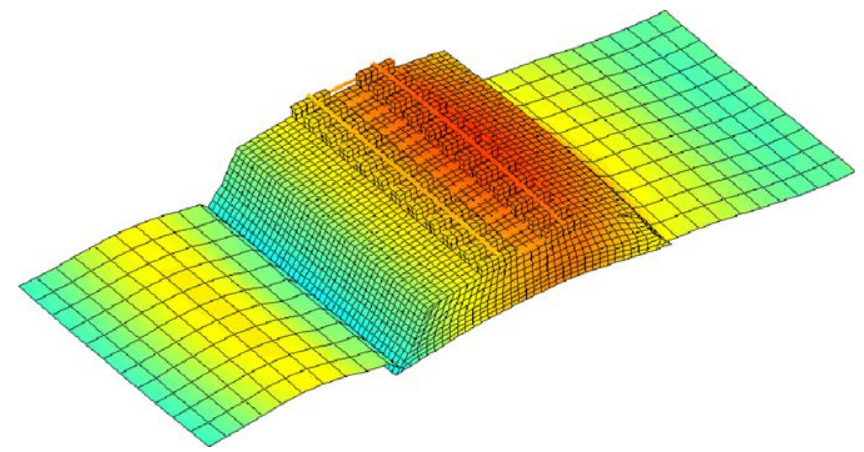

Fig. 15. Response-displacement at $10 \mathrm{~Hz}$ due to a sinusoidal force, at $t=T / 2$.
Figs. 7-12 are related to the ballasted railway track, corresponding to cells $j=0$ (the reference cell, Figs. 7 and 10), $j=+40$ (distance at $+24 \mathrm{~m}$ from the reference cell, Figs. 8 and 11 ) and $j=+80$ (distance at $+48 \mathrm{~m}$ from the reference cell, Figs. 9 and 12). The first figures (Figs. 7-9) show the quantity $\left\|q_{k}^{j}\right\|_{B}^{2}=\int_{B}\left|q_{k}^{j}(\omega)\right|^{2} \mathrm{~d} \omega$ with respect to the associated mode $k$. The last figures (Figs. 10-12) show the graph of $f \mapsto\left|q_{k}^{j}(f)\right|$ (with the frequency $f \in[0,80] \mathrm{Hz}$ ) for the first four modes which have the most important global influence on the frequency band (that is to say with the highest value of $\left\|q_{k}^{j}\right\|_{B}$ ).

The results shown in the precedent figures are associated to the case where the track cell (see Fig. 3) is loaded vertically at a rail point (with the following coordinates $(0.7875$, $0.145,0.336)$ ). In the reference cell (Figs. 7 and 10), it can be seen that the mode 2 (the rigid mode related to the translation on $\mathbf{e}_{\mathbf{z}}$ axis), is predominant. Moreover, since we have

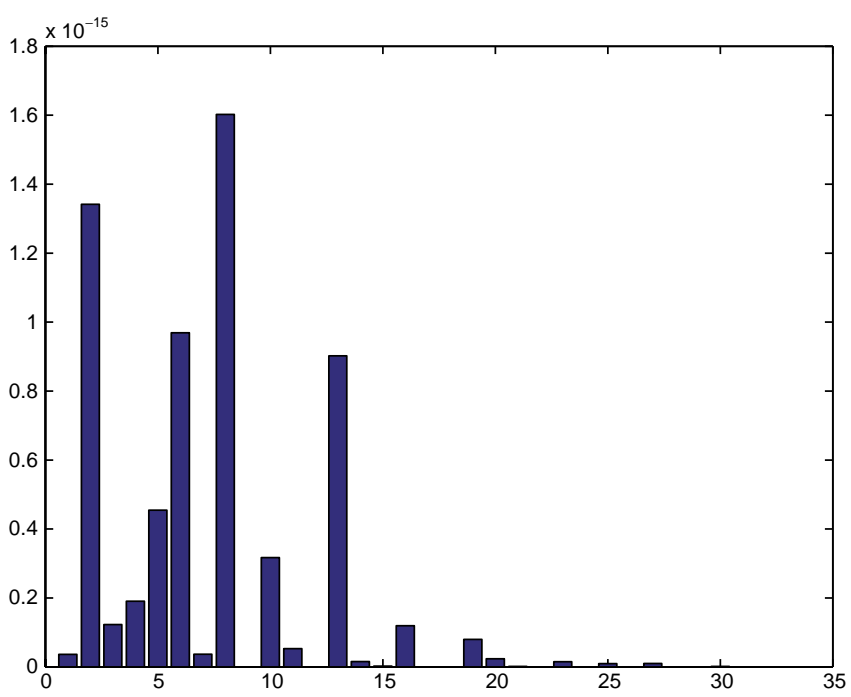

Fig. 16. $\left\|q_{k}^{0}\right\|_{B}^{2}$ with respect to the associated mode $k$.

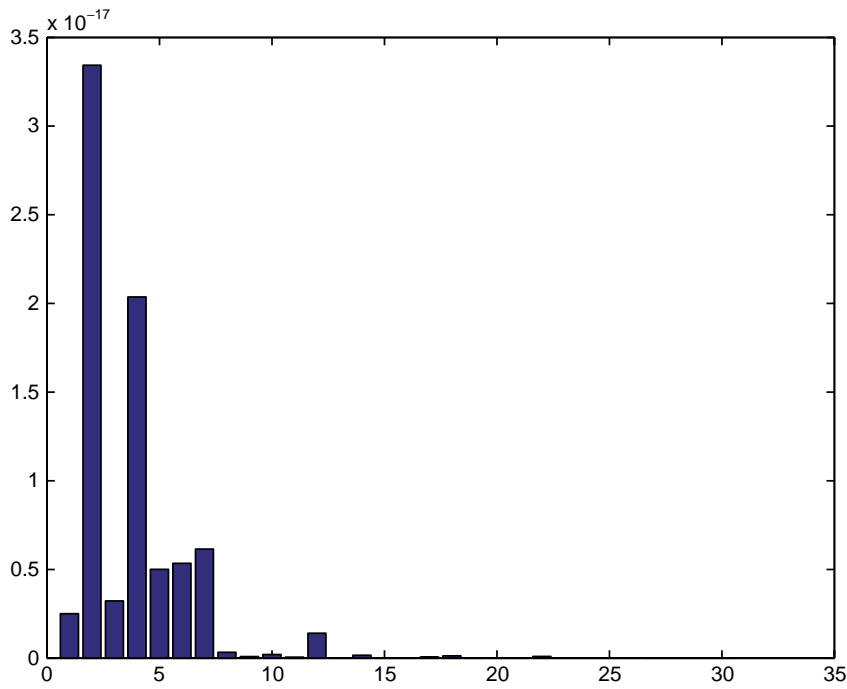

Fig. 17. $\left\|q_{k}^{60}\right\|_{B}^{2}$ with respect to the associated mode $k$. 
an eccentricity of the force position, the $\mathbf{e}_{\mathbf{y}}$-rotation rigid mode 1 and the bending modes $(5,7,12$ and 13) have an influence. For cells far away from the reference cell (Figs. $8,9,11$ and 12), the rigid modes (which correspond principally to $\mathbf{e}_{\mathbf{z}}$-translation and $\mathbf{e}_{\mathbf{y}}$-rotation movements) are predominant: this phenomenon can be explained by the presence of a stiff track on a very soft embankment layer. And their influence is localized in the low part of the frequency range (see Figs. 11 and 12). Finally, it can be noted that the bending mode 5 (see Fig. 13) acts as well.

In Figs. 14 and 15, the displacement-response for the soil-track system due to a sinusoidal force is shown at $10 \mathrm{~Hz}$. A visualization model is then used, in which the generic track is repeated 11 times in the periodicity direction. The reference cell corresponds to the middle cell. The free soil surface has been modeled as well. Then, for the low fre-

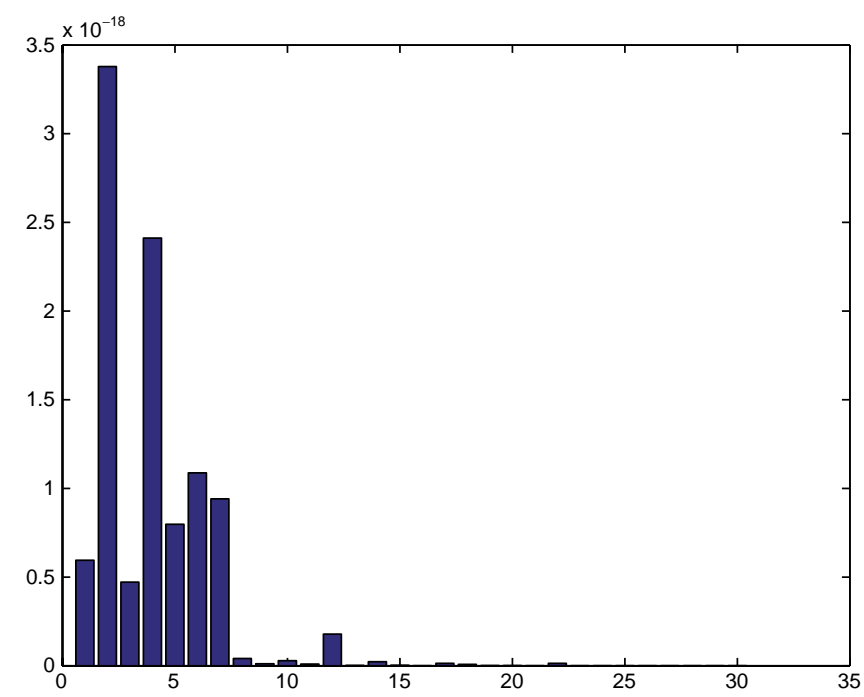

Fig. 18. $\left\|q_{k}^{100}\right\|_{B}^{2}$ with respect to the associated mode $k$.

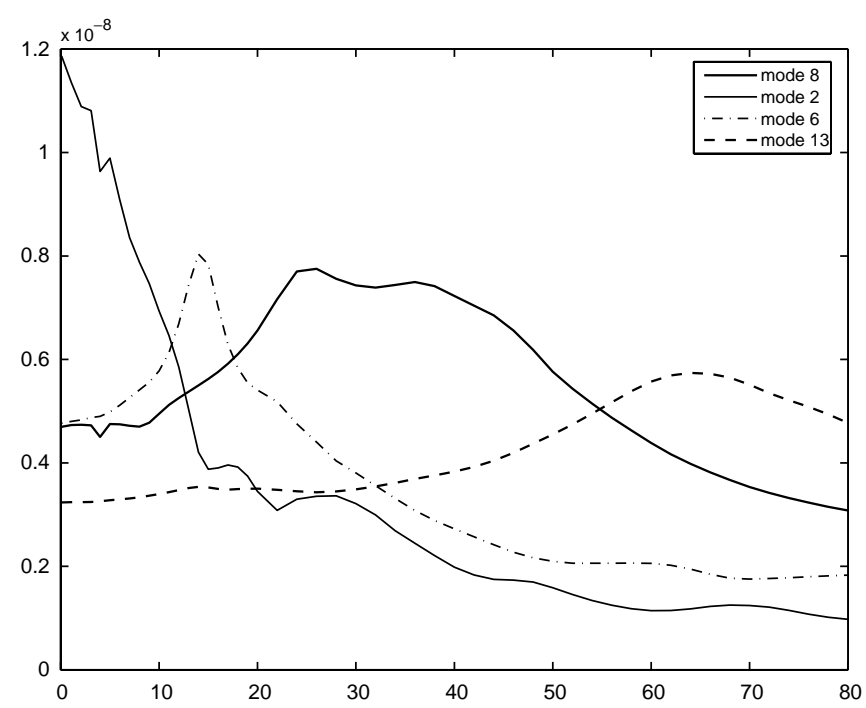

Fig. 19. Functions $f \mapsto\left|q_{k}^{0}(f)\right|$ for the modes $k=8,2,6$ and 13, with $f \in[0,80] \mathrm{Hz}$. quency range, it can be observed that there are mainly bending waves of the track along the structure axis. These observations confirm the results shown in Figs. 7-12.

For the shallow tunnel, Figs. 16-21 show the same quantities and correspond to cells $j=0$ (the reference cell, Figs. 16 and 19), $j=+60$ (distance at $+36 \mathrm{~m}$ from the reference cell, Figs. 17 and 20) and $j=+100$ (distance at $+60 \mathrm{~m}$ from the reference cell, Figs. 18 and 21).

In the considered case, the reference cell (see Fig. 5) is subjected to a vertical force at a point on the tunnel basis (with the coordinates $(-2.5,-0.15,-9.25)$ ). In the reference cell (see Figs. 16 and 19), the rigid $\mathbf{e}_{\mathbf{y}}$-rotation mode 2 and modes causing a bending motion of the tunnel around $\mathbf{e}_{\mathbf{y}}$ axis (the mode 8 for instance) are predominant. Concerning the distant cells (see Figs. 17, 18, 20 and 21),

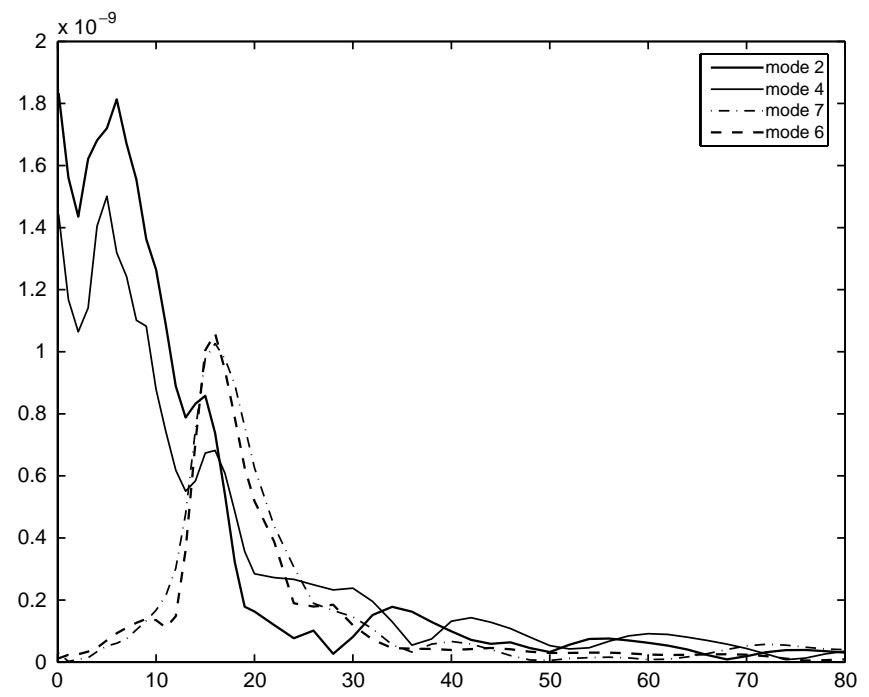

Fig. 20. Functions $f \mapsto\left|q_{k}^{60}(f)\right|$ for the modes $k=2,4,7$ and 6, with $f \in[0,80] \mathrm{Hz}$.

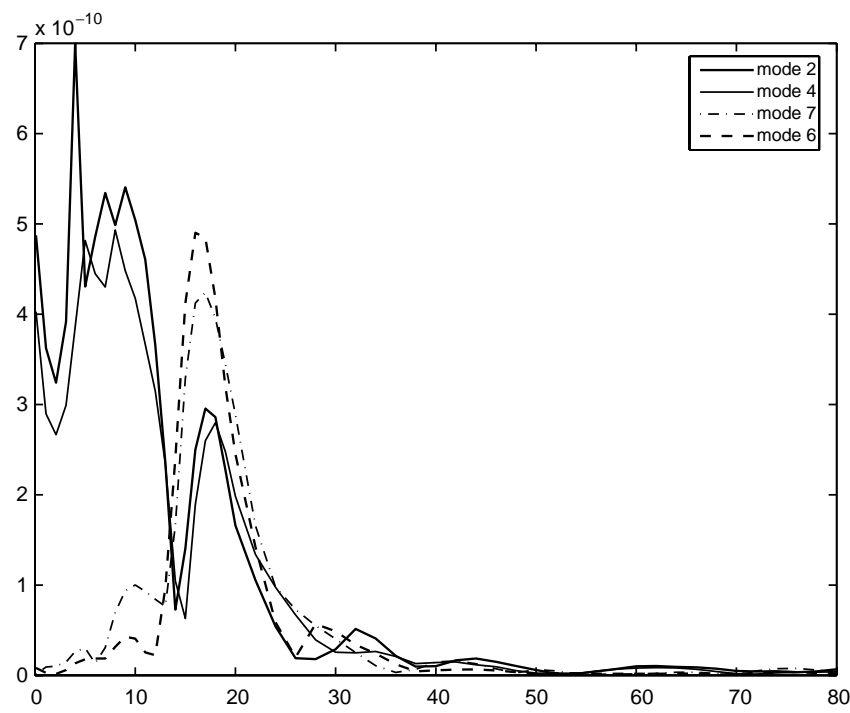

Fig. 21. Functions $f \mapsto\left|q_{k}^{100}(f)\right|$ for the modes $k=2,4,7$ and 6, with $f \in[0,80] \mathrm{Hz}$. 


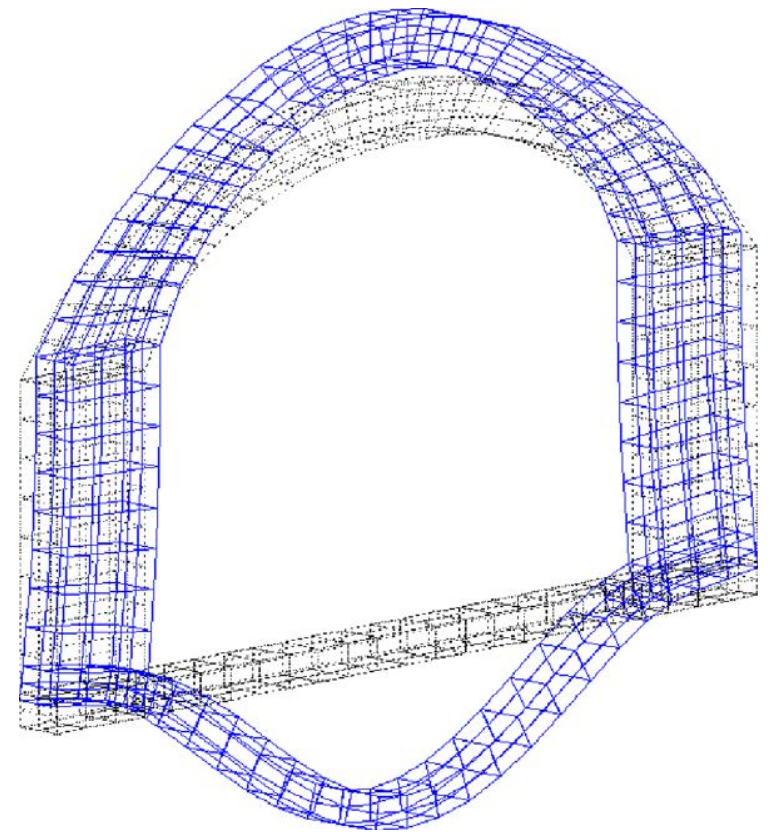

Fig. 22. Periodic mode no. 6.

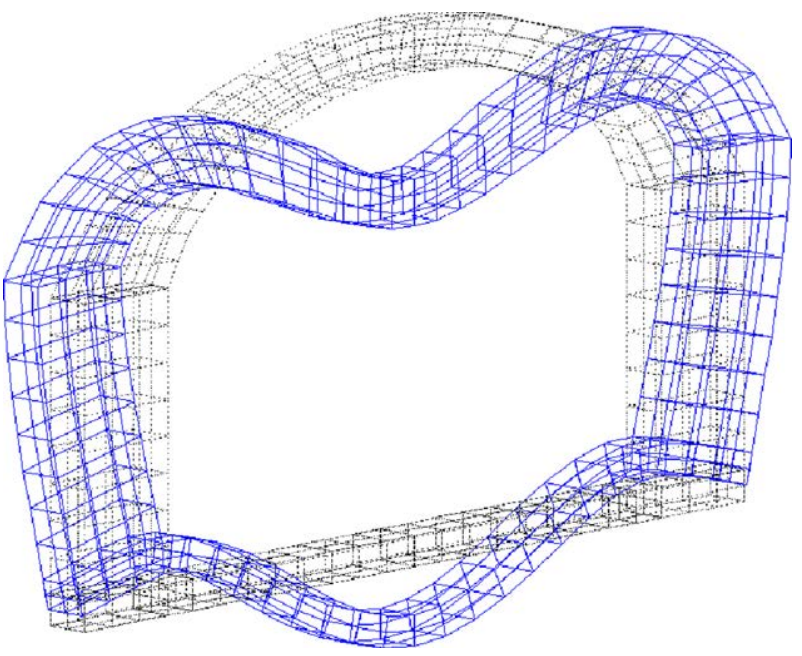

Fig. 23. Periodic mode no. 7.

two main observations can be done: at first, the marked contribution of $\mathbf{e}_{\mathbf{y}}$-rotation rigid modes 2 and 4 . And their effect is principally localized in the low frequency range. Moreover, when the frequency increases, the assertion of the modes 7 and 6 is noticeable. These modes are represented in Figs. 22 and 23.

Consequently, we can conclude that bending and torsion waves of the entire tunnel predominate at low frequencies whereas a propagation of bending waves of the tunnel invert and the roof is generated when the frequency increases. These conclusions corroborate the results of [7] in which it is shown that a wave propagation in the tunnel invert appears for high frequency. In Figs. 24 and 25, the displacement-response of the soil-tunnel system due to a sinusoidal force is shown at $30 \mathrm{~Hz}$. A visualization model

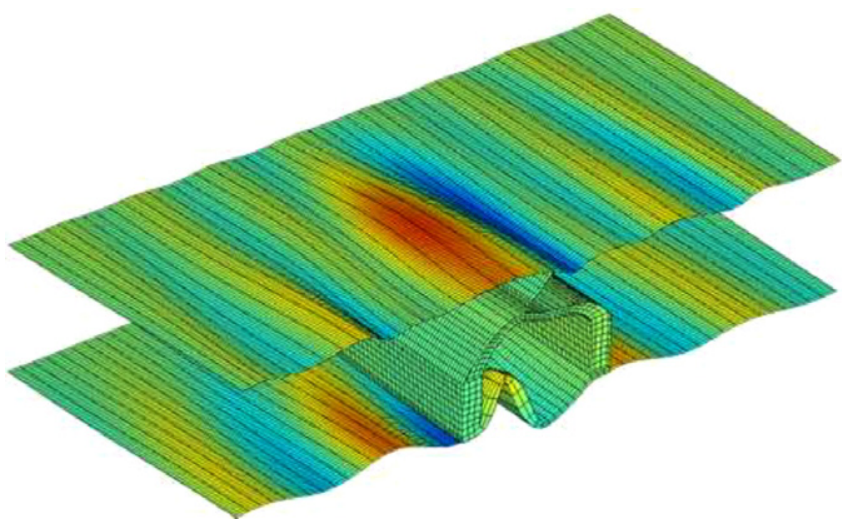

Fig. 24. Response-displacement at $30 \mathrm{~Hz}$ due to a sinusoidal force, at $t=0$.

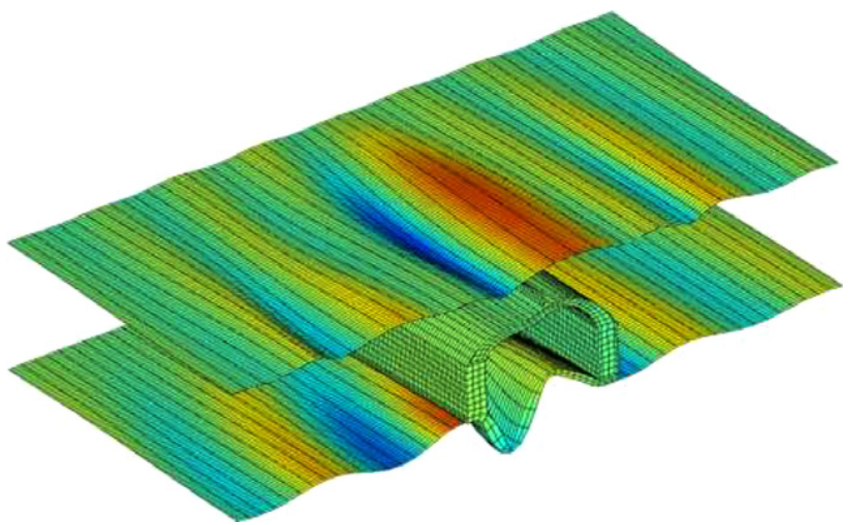

Fig. 25. Response-displacement at $30 \mathrm{~Hz}$ due to a sinusoidal force, at $t=T / 2$.

is used for which the generic tunnel cell is repeated 80 times in the periodicity direction. Three surfaces in the soil are meshed: the free surface, two horizontal surfaces at the depth of the tunnel and a vertical surface between the free surface and the tunnel top. It is observed an important displacement propagation along and perpendicular to the tunnel axis but also in the vertical direction. This phenomenon can be mainly explained by the propagation of the modes 6 and 7 , that is to say modes which induce displacement in the $\mathbf{e}_{\mathbf{z}}$ and $\mathbf{e}_{\mathbf{x}}$ directions (as it can be seen in Figs. 22 and 23).

\section{Conclusions}

A general 3D model for soil-transportation structure is proposed. It is based on a periodic formulation and takes into account the dynamic soil-structure interaction. Different real structures, such as railway track and metro tunnel, are considered highlighting the ability of the method to consider various transportation structures. Moreover, the proposed model has been improved by introducing a general numerical rule for the determination of the optimal number of cells. Finally, the periodic modes propagation has been analysed, offering a global view of the significant dynamical phenomena in the soil-structure system. 
In this paper, the forces which act on the considered transportation structures are static. The proposed method has now to be extended and studied for the (more real) case of moving loads $[11,20]$.

\section{Acknowledgement}

The financial support of the European Community for the projects CONVURT and SUPERTRACK is gratefully acknowledged.

\section{References}

[1] Lombaert G, Degrande G, Clouteau D. Numerical modelling of free field traffic induced vibrations. Soil Dyn Earthquake Eng 2000;19(7):473-88.

[2] Hunt HEM. Modelling of road vehicles for calculation of trafficinduced ground vibrations. J Sound Vib 1991;144(1):53-70.

[3] Al-Hunaidi MO, Rainer JH, Tremblay M. Control of traffic-induced vibration in buildings using vehicle suspensions systems. Soil Dyn Earthquake Eng 1996;15(4):245-54.

[4] Chua KH, Balendra T, Lo KW. Groundborne vibrations due to trains in tunnels. Earthquake Eng Struct Dyn 1992;21(5):445-60.

[5] Metrikine AV, Vrounwenvelder T. Surface ground vibration due to a moving train in a tunnel: two-dimensional model. J Sound Vib 2000;234(1):43-66.

[6] Stamos AA, Beskos DE. Dynamic analysis of large 3-D underground structures by the BEM. Earthquake Eng Struct Dyn 1995;24(6): 917-34.

[7] Clouteau D, Arnst M, Al-Hussaini TM, Degrande G. Freefield vibrations due to dynamic loading on a tunnel embedded in a stratified medium. J Sound Vib 2005;283(1-2):173-99.
[8] Krylov VV. Generation of ground vibration by superfast trains. Appl Acoust 1995;44:149-64.

[9] Sheng X, Jones CJC, Petyt M. Ground vibration generated by a load moving along a railway track. J Sound Vib 1999;228(1):129-56.

[10] Suiker ASL. The mechanical behaviour of ballasted railway tracks. PhD Thesis, Delft Technical University; 2002.

[11] Chebli H, Clouteau D, Modaressi A. Three-dimensional periodic model for the simulation of vibrations induced by high speed trains. Ital Geotech J 2004;38(4):26-31.

[12] CONVURT, Control of Vibrations from Underground Rail Traffic. EC-GROWTH Project G3RD-CT00-00381. <http://www.convurt. com>.

[13] SUPERTRACK, Sustained Performance of Railway Tracks. GROWTH Project G1RD-CT-2002-00777. <http://www.supertrack. no>.

[14] Lombaert G, Degrande G, Clouteau D. The influence of the soil stratification on free field traffic induced vibrations. Arch Appl Mech 2001;71:661-78.

[15] Floquet MG. Sur les équations différentielles linéaires à coefficients périodiques. Ann Ecole Norm 1883:12.

[16] Clouteau D, Elhabre ML, Aubry D. Periodic BEM and FEM-BEM coupling: applications to seismic behaviour of very long structures. Comput Mech 2000;25(6):567-77.

[17] Aubry D. Sur une approche intégrée de l'interaction sismique solstructure. Rev Fr Géotech 1986;38:5-24.

[18] Clouteau D. Propagation d'ondes dans des milieux hétérogènes. Application à la tenue d'ouvrages sous séismes. Thèse de doctorat, Ecole Centrale de Paris; 1990.

[19] Pyl L, Degrande G. Determination of the dynamic soil characteristics with the SASW method at the site of Cite universitaire in Paris, Report BWM-2002-08. Department of Civil Engineering, Katholieke Universiteit Leuven; 2002.

[20] Chebli H, Othman R, Clouteau D. Response of periodic structures due to moving loads. CR Mec 2006;334(6):347-52. 